\title{
Women, Radio Broadcasting and the Depression: A “Captive” Audience from Household Hints to Story Time and Serials
}

\author{
Anne F. MacLennan \\ York University, Toronto
}

The image of women radio listeners during the Depression is unduly influenced by contemporary ideas about daytime serial dramas. This distortion must be revisited in light of new evidence uncovered through content analysis of the program schedule and interview research. Interviews reveal that the conception of listening both as an active and a passive activity took time to develop. Conceptions of and forms of listening served to influence program scheduling. The program schedules evolved slowly and content analysis reveals that women's programming did not fall into an established routine until the latter part of the 1930s.

During the Depression, once the listening audience expanded to include more than the early adopters of new technology and extended beyond the prime-time evening hours, women listeners became an important part of the radio audience. Various indications of a female daytime listening audience become apparent during the 1930s, including children's programs patterned after a mother's day, the shift of serial dramas from the evening to the afternoons and finally reinforcement of early women's programming centering on the home. This study focuses on the interesting case of Canadian women's programming since the audience had access to a truly North American mix of local, network, Canadian, and American programs. A content analysis of radio program schedules in three Canadian cities supplemented by oral history interviews to clarify the place and role of women listeners' and women's programming in radio during the Depression are the foundation of this work. ${ }^{1}$

Radio made the transition from an occupation of the hobbyist to a medium for regular entertainment for a variety of listening audiences. In its early years and immediately following the First World War, radio was regarded as primarily the domain of the hobbyist, whose numbers rapidly multiplied thanks to training received in the military. Messy, leaking, homemade contraptions, the radio was usually confined to space in barns, garages, and attics. Although the hobbyists were almost exclusively boys and young men, Michelle Hilmes demonstrates through an extensive list of articles from QST, the journal of the American Radio Relay League and the Radio World column "Radio and Women”, that some women were also active in amateur radio. ${ }^{2}$

\footnotetext{
${ }^{1}$ This work draws on the earlier sample for Anne Frances MacLennan, "Circumstances Beyond Our Control: Canadian Radio Program Schedule Evolution During the 1930" diss., Concordia University, 2001. The sample is a strategic random sample of the Halifax, Montreal and Vancouver radio broadcast schedules published in local newspapers, 1930 to 1939. The sample from the decade of the 1930s had a parameter of 515 weeks, including Sunday, December 29, 1929 to Saturday, January 6, 1940. The sample has been extended to include a parallel sample of Winnipeg and Toronto. The content analysis is supplemented by a convenient and snowball sample of oral history interviews of remaining audience members.

${ }^{2}$ Although the popular perception is that the hobby was the domain solely of boys and young men, Michele Hilmes uses an extensive list of articles from QST, the journal of the American Radio Relay League, to demonstrate that women were also active in amateur radio for many of the same reasons as their male counterparts, and Hilmes suggests that the "ability to escape the determinations of gender" may have added to radio's appeal. Michele Hilmes, Radio Voices: American Broadcasting, 1922-1952 (Minneapolis: University of Minnesota Press, 1997) 132-136;
} 
While the experimenters and hobbyists were among the first radio enthusiasts, radio quickly moved beyond a fad or craze to a permanent part of the domestic sphere.

While radio remained almost strictly experimental it was associated with a male audience, but its role changed as the medium grew in popularity. In Great Britain, almost 85 percent of the country was within reception range of the eight stations established by $1923 .^{3}$ While only 21 percent of households possessed a radio license in 1926 that percent steadily rose to 64.4 percent by $1936 .{ }^{4}$ With a larger geographical expanse to cover, American radio stations rose from a mere 5 stations in 1921 to 765 in $1940 . .^{5}$ In 1924, 11.1 percent of Canadian households owned radios and 81.1 percent in $1940 .{ }^{6}$ Canada's scattered population and large land mass made radio coverage more difficult, starting with 51 stations in 1923 and 0.5 percent of households licensed for radio receivers there were 94 stations and 47 percent of households with licensed radio receivers in $1939 .{ }^{7}$ Evasion of licensing in Canada due to resentment over having to pay for what was perceived to be free across the border in the United States and since many listeners lived within in reception range of American stations account in part for what might be a less apparent spread of radio in Canada.

Beyond the growth of the radio audiences and radio reception, the entertainment value of radio soon became more important. Richard Butsch notes that in "[t]he 1920s [there] was a distinct turning point in gender roles ... [that included] assertions of women's competence with technology." 8 As radio became more of a "domestic furnishing" rather than a hobby, radio was effectively transferred from "the traditional masculine sphere of technology to the feminine domestic sphere." ${ }^{9}$ Women listening to daytime radio were a unique element of early radio and a

Susan Smulyan, "Radio Advertising to Women in Twenties America: A Latchkey to Every Home,” Historical Journal of Film, Radio \& Television 13 (1993) 3 of 18 online.

${ }^{3}$ Lyn Gorman and David McLean, Media and Society in the Twentieth Century. (Malden: Blackwell Publishing, 2003) 53.

4 “Licence figures,” BBC Handbook 1939, 1929 as cited in “Table 1.1” Jennifer Doctor, The BBC and Ultra-Modern Music, 1922-1936: Shaping a Nation's Tastes (Cambridge: Cambridge University Press, 1999) 20.

${ }^{5}$ Data derived from Broadcasting Yearbook 1977 as cited in Christopher H. Sterling and John M. Kittross, Stay Tuned: A Concise History of American Broadcasting. 2nd ed. (Belmont, California: Wadsworth Publishing Company, 1980) 633.

${ }^{6}$ Sterling and Kittross, 633; Thomas Eoyang, “An Economic Study of the Radio Industry in the USA” diss., Columbia University 1936, 67 and Christopher Sterling and Timothy Haight, The Mass Media: Aspen Institute Guide to Communication Industry Trends. (New York: Praeger, 1978) 360, 363, 367 as cited in Richard Butsch, The Making of American Audiences: From Stage to Television, 1750-1990. (Cambridge: Cambridge University Press, 2000) 176.

7 “Radio Telephony,” Canada. Dominion Bureau of Statistics. General Statistics Branch, The Canada Year Book 1925 (Ottawa: King’s Printer, 1925) 660; “Part VII. Radio Communications,” Canada. Dominion Bureau of Statistics. Department of Trade and Commerce, Canada, The Canada Year Book 1940 (Ottawa: King’s Printer, 1940) xx-xxi, 721-722; F. H. Leacy, ed., “A.1 Estimated population of Canada. 1867-1977.” “A248-253 Number of households and average number of persons per household, Canada 18811976.” Historical Statistics of Canada. 31 July 2006 http://www.statcan.ca/english/freepub/ 11-516-XIE/sectiona/A1.csv, http://www.statcan.ca/english/freepub/11-516-XIE/sectiona/ A248_253.csv

${ }^{8}$ Butsch, 184.

${ }^{9}$ Butsch, 185. 
part of a larger sense of the routinization of audience listening patterns. Lesley Johnson and Simon Frith argue that radio ceased to be an intrusion but part of the escape and common culture of the home. ${ }^{10}$ In A Social History of British Broadcasting: Serving the Nation, Volume One 1922-1939, Paddy Scannell and David Cardiff explain important transformations in the rise of popular radio in the 1930s that included the routinization of program schedules, the changing style of radio talk and the end of the concept of a unified audience. ${ }^{11}$ The growth of the audience followed by the development of a pattern of listening was common to the development of Australia, the United Kingdom, the United States, and Canada.

The rapid spread of radio in North America led to its commercialization, a feat more easily accomplished in the United States where the audiences were large and densely concentrated. Susan Smulyan argues that the rapid commercialization of radio soon led to the serious consideration of the medium's daytime audience and the consideration of women as a potential audience for programming and the accompanying advertising. ${ }^{12}$ Smulyan addresses the changeover of radio from a male-dominated medium that did not include daytime programming at all in 1924 to one that considered the emerging consumer culture based on the home and family. ${ }^{13}$ American radio stations rapidly became part of the NBC Red, NBC Blue, or CBS network. As radio stations in the United States rapidly commercialized, they expanded their daytime schedules and became increasingly standardized with regard to content and technical standards. By 1933, the independent broadcasters with religious, educational and other motivations had virtually disappeared, largely becoming part of the major networks of NBC Red, NBC Blue, or CBS. ${ }^{14}$ The networks provided a lot of the major entertainment supplied by the stations, which served to quickly homogenize the type of broadcasting heard across the United States and Canada.

Canadian radio remained in its infancy throughout the 1920s, but by the 1930s most Canadian radio stations were attempting to become full-time broadcasters with a daytime and evening schedule. Many Canadian listeners were accustomed to tuning in to American network programming in the evening, when and where reception was possible. However, once the Canadian broadcasters considered the daytime audience, they started to vary programs for their perceived audiences. Women became a new audience to be taken into account by early radio broadcasters, not only for commercial motives as demonstrated by Smulyan in the American case, but simply as an attempt to fill the broadcast day by matching the routine of their perceived listeners. Women and children's programming had not been much of a consideration for early broadcasters, as they were barely able to fill the schedule with an assortment of musical

\footnotetext{
${ }^{10}$ Lesley Johnson, “Radio and everyday life: The early years of broadcasting in Australia, 1922-1945,” Media, Culture \& Society (April 1981): 167; Simon Frith, “The Pleasures of the Hearth,” in Tony Bennett and Victor Burgin, eds., Formations of Pleasure (London: Routledge \& Kegan Paul, 1983).

${ }^{11}$ Paddy Scannell and David Cardiff, A Social History of British Broadcasting: Volume One 1922-1939 Serving the Nation (Oxford: Basil Blackwell, 1991).

12 Smulyan, "Radio advertising to women in twenties America."

${ }^{13}$ Susan Smulyan, Selling Radio: The Commercialization of American Broadcasting 1920-1934 (Washington: Smithsonian Institute Press, 1994).

${ }^{14}$ Robert W. McChesney, Telecommunications, Mass Media, and Democracy: The Battle for the Control of U.S. Broadcasting, 1928-1935 (New York: Oxford University Press, 1993).
} 
recordings and local amateur talent. As the stations grew and Canada's own networks were established, more of such programming gained a place in the schedules across the country.

Only small regional networks were the norm in the late 1920s and 1930s. The Canadian National Railways network, formed in 1924, provided the skeleton of a potential for national network broadcasting until the formation of the Canadian Radio Broadcasting Commission (CRBC) in 1932 and its successor the Canadian Broadcasting Corporation (CBC) in 1936. Thus, local and independent broadcasters remained an important element of Canadian broadcasting due partly to the very tentative beginnings of networks in the 1920s and 1930s. While the popular contention or belief is that American network broadcasting dominated all of Canadian broadcasting, this is far from true. While a large proportion of the Canadian population living along the border had access to American programming, reception was not always reliable and it was confined to the evening hours. Women listening during the evening often represented part of a family group so programming dedicated to the female listener did not receive placement in the evening schedule. Daytime broadcasting which was decidedly devoted to the domestic sphere, developed somewhat independently of American networks because of the lack of access in many cities and towns to American programming during the day. ${ }^{15}$

Thus, certain genres of programs were allowed to develop somewhat independently of American codes and standards due to the lack of daytime competition from American networks. Women and children's programming were among these programming genres that, at least initially, escaped the influence of the larger trends relying instead on independent local productions. With the establishment of a growing audience, Canadian stations sought in a similar fashion to that of American networks to set a routine program day from morning to night. Due to the unavailability of American programs during the day, Canadian stations were permitted to develop independently of that influence in large part for daytime programs until the arrival of the CBC. The daytime schedule was routinely supported by extensive use of performed and recorded music, but in a quest for program diversification in increasingly competitive markets, local and inexpensive programming was produced often in genres generally neglected or left over by the networks. Thus, talk, religious, news, sports, women's and children's programming became one of the local station's unique resources. ${ }^{16}$

While a number of different programming genres were closely associated with women audience members, those of greatest interest were general women's programming devoted to health, talk, meal preparation and other topics of interest, serial drama, and children's programming which tended to work around not only the child's schedule but primarily that of their mothers. Serial dramas, the type of 1930s radio programming that may most readily jump to mind, were almost exclusively American programs, children's programming was mixed in terms of its format and origins, and the general woman's program scheduled during the day was most likely a local Canadian production.

\footnotetext{
${ }^{15}$ Evening broadcasts, dependent upon sky waves rather than daytime ground waves, would have had a wider field of reception. During the day the D layers of the ionosphere absorbed the sky waves. At night, however, sky waves were reflected by particles in the $\mathrm{E}$ and $\mathrm{F}$ layers that were not blocked by the D layer, which did not absorb light at night. Thus, radio signals would easily extend much further than was the case during the day.

${ }^{16}$ MacLennan.
} 
The serial drama came into its own in the 1930s, blossoming into a huge industry that eventually made the crossover to television. The image of women listeners as the devoted audience of the serial drama is most closely associated with the period, but it took until the latter part of the 1930s for serial dramas to emerge as daytime listening fare. Michele Hilmes notes that serial dramas such as The Rise of the Goldbergs, Clara, Lu and Em, Myrt and Marge, and Just Plain Bill were broadcast for their first few years in the evening but that by the mid-1930s the networks cleared the evenings of serial drama. ${ }^{17}$ She also cites Variety's 1936 statistics, which indicate that the network daytime schedule consisted of 55.3 per cent serial drama, 16.1 per cent "talks", and 11.4 per cent juvenile programs. ${ }^{18}$ Content analysis of the program schedules sampled for this study makes it possible to pinpoint the shift of the bulk of the serial dramas to the afternoons in $1936 .{ }^{19}$ The shift of these live serial dramas to the afternoon on the East Coast meant that they would be part of the morning and early afternoon schedule on the West Coast.

This was the juncture when the serial drama also became an important element of the schedules of West Coast American stations, not only as evening entertainment on the East Coast. The genre was almost exclusively American in origin, virtually uncontested in Canada, as shown in Table 1. The increase in the distribution of serial drama through networks and electrical transcriptions accounts for its added contribution to the schedule. Rather than being immediately expelled from the evening schedule, the serial dramas drifted away from it by the end of the decade as they slowly became part of the daytime listening schedule.

\section{TABLE 1}

Percentages of broadcast duration of American and Canadian content of serial drama programming in the overall Vancouver radio schedule, not including unidentified programs, 1930 to 1939

\begin{tabular}{|l|l|l|l|l|l|l|l|l|l|l|}
\hline Origin & 1930 & 1931 & 1932 & 1933 & 1934 & 1935 & 1936 & 1937 & 1938 & 1939 \\
\hline $\begin{array}{l}\text { American } \\
\text { Content }\end{array}$ & 0.53 & 0.97 & 1.79 & 1.02 & 0.78 & 1.48 & 1.78 & 3.13 & 3.40 & 4.70 \\
\hline $\begin{array}{l}\text { Canadian } \\
\text { Content }\end{array}$ & 0.03 & 0.21 & 0.28 & 0 & 0.03 & 0.04 & 0.04 & 0.22 & 0.14 & 0.11 \\
\hline
\end{tabular}

The meager showing of serial drama on the American West Coast stations was altered in a positive way by the decision on the East Coast that the genre was better suited to the afternoons. A long-neglected component of the evening schedules of Western stations KOMO, KIRO, KOL, and KJR, in mid-decade serial drama became a consistent part of the West Coast schedules, mainly in the daytime. The scheduling move made the genre palatable and even desirable on the West Coast. For example, Arnold Grimm's Daughter, broadcast by CBS at 1:30 p.m. on the East Coast, appeared on West Coast stations of CBS at 10:30 a.m. By 1936, serial dramas were suddenly dispersed throughout the West Coast schedule and they experienced

\footnotetext{
${ }^{17}$ Hilmes, 151.

${ }^{18}$ Edgar A. Grunwald, “Program-Production History, 1929-1937,” Variety Radio Directory 1937-1938 (New York: Variety, 1937), 28 as cited in Hilmes, 151.

${ }^{19}$ This was clearly the case on the East Coast; Montreal and Toronto schedules were directly affected by the decisions of the American networks on the East Coast and their changing priorities.
} 
tremendous growth over the next three years. In the last years of the decade musical and variety programs were scheduled in the evening spots that had previously been filled by serial dramas. Electrical transcriptions also contributed to the newly discovered success of serial drama on the West Coast, because they could be positioned in the schedule at a time suited to the station rather than the network.

Serial dramas were numerous and diverse. From the midpoint until the end of the decade the varied programs included: The Affairs of Anthony, Your Family and Mine, Houseboat Hannah, Ma Perkins, Dan Harding’s Wife, Young Hickory, Guiding Light, Backstage Wife, The Story of Mary Marlin, The Rise of the Goldbergs, Stella Dallas, Big Sister and an assortment of others too extensive to list. The generous supply of serial dramas meant that exposure to specific programs was inconsistent across the continent. Except for very well-established and longrunning programs such as Ma Perkins, which ensured their extended reach beyond the networks with the assistance of electrical transcriptions, only rarely was there a common national experience of these programs. The Canadian experience of this genre was derived almost entirely from sources in the United States, largely programs broadcast by American stations on Canadian and American networks. It is, however, important to note that the scheduling of the serial dramas, initially during the evening, indicated that they were not conceived strictly for women's daytime entertainment. The scheduling of the serial dramas inconsistently across the country due to the difficulties with time zones and distribution meant that the experience of the serial drama differed for women across Canada and the United States in terms of the program's place in the day and selection.

Timing was crucial to serial drama as it was to other genres such as comedy. Although the literature firmly places the radio within the domestic sphere by the 1930s, a number of factors contributed to the variation in women's listening patterns. The type of radio purchased for the family contributed to changes in women's listening routines, and the location of the radio in the home was crucial to the type of listening that occurred.

Larger, more expensive floor models were more likely to be positioned in the parlor or living room, smaller kits might be in possession of a child, and the table tops of the 1930s could be anywhere in the house. The crystal sets made from cereal boxes using diagrams in the pages of local newspapers were frequently the only radio many Canadian families owned until the latter part of the 1930s, when reception was widened by the slow extension of the CBC network, finally covering 84.2 percent of the country in time for the Royal Tour in $1939 .{ }^{20}$ The radio, however, remained a luxury for many. The lack of technical restrictions that put many small broadcasters out of business in the United States, but kept broadcasting alive in Canada also catered to inexpensive radio equipment that did not allow for a great deal of tuning. Regulation made shared frequencies the norm in most Canadian cities, allowing listeners to leave their dial tuned to one frequency. As radios became more sophisticated, they immediately first rose in price with the introduction of expensive floor models for the parlor, but innovations as early as 1931 allowed for the table top model to become one of the most popular styles of radios, due largely to its price. Butsch charts the rise and fall of radio prices in the United States, noting that

\footnotetext{
${ }^{20}$ Canadian Broadcasting Corporation, Canadian Broadcasting: An Account of Stewardship, excerpted from Canada. Parliament. House of Commons. Special Committee on Radio Broadcasting. Minutes of Proceedings and Evidence, Nos. 2 and 3 (Ottawa: King’s Printer, 1939) 11.
} 
the average price started at $\$ 50.00$ in 1924 , rose to a peak of $\$ 133.00$ in 1929 , and then fell to $\$ 40.00$ by $1940 .{ }^{21}$ In a similar trend, the 1925 average unit price was $\$ 46.95$ in Canada. ${ }^{22}$ The average unit price in 1930 reflected its size and style at $\$ 112.87$ when impressive floor models dominated..$^{23}$ In 1931, mantel sets were introduced, production was increased and the average unit price fell to $\$ 63.61 .^{24}$ By 1939 , the average unit price had fallen further still to $\$ 24.90 .^{25}$ Despite the fluctuations in price the average radio represented three weeks' wages for the average male in 1931 and over a week's salary in $1941 .{ }^{26}$ At that price the radio often remained in a place of honor whether it was a tabletop or floor model.

Although the first primitive receivers, crystal sets, were cheaper and easier to assemble, the physical constraints of earphones ensured that radio listening continued to be a solitary pleasure, impossible for a group to partake of together. In an effort to make radio a larger communal experience, tabletop radios and floor model radios in cabinets were available fully assembled in the 1920s and 1930s, catering to a wider audience of listeners. While the nature of the listening audience as active or passive was a significant consideration for the potential of the daytime audience. Susan J. Douglas distinguishes between the different norms for radio listening during the twentieth century " . . . whether curled up in our beds, sitting in the living room with our families, or blasting around in our cars ...” demarking the different eras of radio. ${ }^{27}$ Radio of the 1930s is most closely associated with the image of active listening and the family gathered around the radio together.

A woman listener, however, was more likely to listen to the radio if she could do so passively, overlapping with her other household activities. Listening habits varied with the region, circumstances, place of the respondent in the family, and availability of the leisure time to listen to the radio. A family who received the radio as a Christmas present eagerly shared the radio, each member having a preference: the brother sports, the respondent loved music, and her father having already established a pattern of listening to the news on a neighbor's radio continued to listen to the news. Two respondents indicated that given the economic circumstances of the time, electricity was viewed to be an expensive commodity not to be frivolously wasted. In each case, radio listening was very specifically selected by a parent and turned off immediately after the chosen program ended. A newlywed having access to a variety

\footnotetext{
${ }^{21}$ Christopher Sterling and Timothy Haight, The Mass Media: Aspen Institute Guide to Communication Industry Trends. (New York: Praeger, 1978), 360, 363, 367 as cited in Butsch, 176.

${ }^{22}$ Canada. Dominion Bureau of Statistics. Department of Trade and Commerce. Mining, Metallurgical and Chemical Branch. Manufactures of the Non-Ferrous Metals in Canada 1930-1932 (Ottawa: King's Printer, 1934) Table 111, 79.

${ }^{23}$ Manufactures of the Non-Ferrous Metals in Canada 1930-1932, 62.

${ }^{24}$ Manufactures of the Non-Ferrous Metals in Canada 1930-1932, 62.

${ }^{25}$ Canada. Dominion Bureau of Statistics. Department of Trade and Commerce. Mining, Metallurgical and Chemical Branch. Manufactures of the Non-Ferrous Metals in Canada 1939-1943 (Ottawa: King's Printer, 1946) Table 82, 99.

${ }^{26}$ Canada. Dominion Bureau of Statistics. Seventh Census of Canada Volume V (Ottawa: King's Printer, 1935), 23; Eighth Census of Canada Volume 6 (Ottawa: King's Printer, 1945), 4-5.

27 Susan J. Douglas, Listening In: Radio and the American Imagination. (Minnesota: University of Minnesota Press, 1999) 6.
} 
of stations in Canada's largest city at the time, declared that the radio played all day long and much of the evening.

Although some listeners felt enriched by the content that the programs brought into their homes, others viewed it as difficult to schedule into their busy days. One Toronto listener explained that the radio was not for children, they listened to one daily program, a favorite of her mother's. While it was on for 30 minutes all activity ceased and everyone "stood around to listen to the program.” Two respondents indicated that the children in their family waited in line for their respective turns to listen to the radio. Others, usually the mothers or older daughters, noted that family responsibilities absorbed so much of their time that there was no time to listen to the radio, seeming to indicate that some perceived listening during the 1930s as active rather than a passive background companion.

In most cases, the listeners eagerly waited their turn for the radio or listened actively not allowing daily tasks to intrude on their listening time. A newlywed who listened all day completed her housework with the radio for company. In the case of the Belleville, Ontario mother taking care of three young daughters took precedence; only in the evening did she sit with her husband to listen to the radio and even then recalls knitting or doing crochet work in her lap as she listened. Only slowly, perhaps as the technology adjusted to women's routine, did the radio become a passive activity and a regular element of the day.

Children's programming indirectly formed part of the woman listener's day. While some programs were scheduled immediately after school, none were broadcast during the day for preschool children and this genre of programming was also clustered around bedtime, setting up a routine and just prior to supper, allowing women to occupy small children while they went about preparations for supper.

In a similar fashion to serial drama, it took time for children's programs to find their place in the radio schedule. Children's programming remained a standard part of American radio programming throughout the decade; however, as its format evolved the genre was inconsistently placed in the schedules of American stations of different regions. Like talk, children's programming presented an opportunity to develop inexpensive independent programs, largely of the "Auntie" and "Uncle" or story-time variety, using local talent to tell stories and sing songs. The programs appeared habitually in the daytime time slot after school, in the late afternoon and at bedtime. These types of programs appeared in the schedules of East Coast stations, but lacking any standard network-issue programs, West Coast stations opted to broadcast no children's programming at all.

Even after the arrival of a standard children's format of juvenile serial dramas, the genre remained neglected by West Coast stations. The difference in time zones meant that some of the time slots habitually filled with children's programming, particularly in the late afternoon, were occupied by live vaudeville-style comedy. Likewise, when variety was shifted to the earlier afternoon slots it left few optimal positions for children's programming in the schedule. As a result children's programs that enjoyed years of popularity on the East Coast were only routinely introduced to West Coast schedules in 1937 after comedy moved to later evening spots and serial drama was shifted to the morning and early afternoon. Despite the innovative efforts in the realm 
of children's programming put forward by the networks, adult programming took precedence on the West Coast. Although long a part of the American network schedule, children's programming only grew in Vancouver, Montreal and Halifax when these programs were more widely available through electrical transcription in the latter part of the decade, as indicated in Table 2.

\section{TABLE 2}

Average percentages of broadcast duration of American and Canadian children's programming in the full radio schedules of Vancouver, Montreal and Halifax, not including unidentified programs, 1930-1939

\begin{tabular}{|l|l|l|l|l|l|l|l|l|l|l|}
\hline Origin & 1930 & 1931 & 1932 & 1933 & 1934 & 1935 & 1936 & 1937 & 1938 & 1939 \\
\hline $\begin{array}{l}\text { American } \\
\text { Content }\end{array}$ & 0.48 & 1.41 & 2.13 & 1.17 & 1.20 & 1.51 & 1.76 & 2.25 & 3.31 & 2.26 \\
\hline $\begin{array}{l}\text { Canadian } \\
\text { Content }\end{array}$ & 0.33 & 0.66 & 0.63 & 0.63 & 0.60 & 1.22 & 1.24 & 1.39 & 1.10 & 0.93 \\
\hline
\end{tabular}

The introduction of the children's program Little Orphan Annie was pivotal to the development of the genre. It marked the start of the juvenile radio serial drama, a genre in and of itself, and it set the pattern for the development of American children's programming for the decade. First aired by WGN in Chicago in 1930, but quickly picked up by the NBC Blue network, which aired the program from April 6, 1931 to January 19, 1940, it was broadcast at 5:45 p.m. weekdays. ${ }^{28}$ Little Orphan Annie was the catalyst for the explosion of juvenile drama that included such long-running favorites as The Lone Ranger, Treasure Island, Jack Armstrong, Tarzan, Chandu the Magician, Howie Wing, Dick Tracy, Popeye the Sailor, The Green Hornet, Speed Gibson, and Buck Rogers. As ongoing dramas, similar to the serial drama, the programs developed a regular and loyal set of fans.

The secondary type of American children's program was juvenile repertory. The genre included Our Barn, from 1936 to 1941, The Children's Hour, and NBC's Coast to Coast on a Bus. Let's Pretend, however, remained the most successful of this genre, running on CBS from September 7, 1929 to October 23, 1954, featuring children's fairy tales and employing child performers. ${ }^{29}$ By the decade's end, then, the field of children's programming encompassed two popular subgroups: juvenile drama and juvenile repertory.

The programs had limited distribution in Canada; access to American stations only in the evening effectively cutting the broadcast time in half. While Canadian children's programs did not encompass the same quantity or variety of juvenile serial drama or repertory, the continued use of the "Auntie" and "Uncle" programs allowed them to maintain a consistent place in the

\footnotetext{
28 The program was aired concurrently by Mutual from November 2, 1936 to January 19, 1940. Dunning, John. On the Air: The Encyclopedia of Old-Time Radio. (New York: Oxford University Press, 1998) 402-403; Swartz, Jon and Robert C. Reinehr. Handbook of Old-Time Radio: A Comprehensive Guide to Golden Age Radio and Listening and Collecting. (Metuchen, New Jersey: The Scarecrow Press, Inc., 1993) 76-77, 86. The lack of any evidence that the program was distributed by electrical transcription in the schedule and its late arrival on the West Coast indicated that it was available solely through the network in the 1930s.

${ }^{29}$ Miriam Ross was well known as a young child for her toothless witch cackle, but played a range of other roles. Louie Rosella, “Miriam Ross, 78, radio actress,” The Toronto Star 5 October 2000: B5.
} 
schedule and children's programming was another 'gold mine' for the local independent radio station that hoped to diversify programming largely with its own staff or local talent. CHNS in Halifax started the decade with Halifax Herald's Children's Period with Pollyanna, which lasted until 1938. The CRBC network contributed Children's Corner from Montreal in 1933, followed up with Lullaby Lagoon in 1936, but CHNS also continued to develop its own children's programming. One long-lasting success was Uncle Mel. In 1934 Senator Dennis of The Halifax Herald hired Hugh Mills, already working as an actor at CHNS, to read the comic strips from his newspaper to boost circulation, starting the eighteen-year run of Uncle Mel. ${ }^{30}$ The dramatic expansion of children's programming after 1936 was the product of a combination of locally developed programming and the American programming introduced by the CBC. Light Up and Listen Club was the CBC's own contribution to children's programs, but it also introduced the American Howie Wing and Dick Tracy. The genre was clustered conveniently at bedtime and after school but closer to the time of day when mother would be preparing supper. Thus, diversification of children's program offerings and the essential placement within the schedule guaranteed the children's program a place in women and children’s listening day.

In many cases woman's daytime programming became one of the mainstays of the local station. Daytime women's programs focused on talk and information; they were independently produced and occupied a space in the schedule that rarely competed in the Canadian context with American stations or network programs. In 1931, CKMO in Vancouver introduced Betty Lee, which became the backbone of its women's programming for the decade. Later in the decade, CKWX, a competitor, also picked up the program. Not only was it a major addition to the 1931 schedule since it was aired regularly in the morning and afternoon schedules, 30 minutes five times a week by 1939, Betty Lee became one of the essential ingredients of the daytime schedule. The development of women's programming was comparable to the emergence of serial drama at CJOR in Vancouver in the late 1930s. No women's talk programs appeared in the schedule at all until the local Women's Point of View in 1935, followed by Women's Column of the Air in 1936 another local program broadcast six times a week, replaced by For Women Only in 1937. At their peak, women's talk programs reached 11.79 per cent of the schedule on CJOR. Good Morning Neighbor, Sue's Notebook and the American Radio Kitchen formed part of the roster. Radio Kitchen was dropped the following year, but the other two new programs were broadcast regularly, having found their niche. CJOR's adoption of a large amount of American serial drama was counterbalanced by the simultaneous development of its own women's programming.

Women's programs presented a logical extension of the talk program format. To an even greater degree than talk programming, most women's programs were local; the ongoing Bonjour Madame with Jovette Bernier appeared on CKAC, Montreal's largest bilingual broadcaster, as early as 1931 and Daily Menu appeared in 1930. In 1937, CKAC attained its peak of women's programming with an average of 4 hours and 33 minutes per week, featuring Bonjour Madame and Feminine World six times a week. The frequency and regularity of specific programs were characteristic of women's programming. Among the other inclusions for the decade were Women's Programme and Women's Page. The regularity of these programs and their anonymous presentation in the schedule was revealing. Unlike other local talk programs listed in The

\footnotetext{
${ }^{30}$ Hugh Mills as cited in McNeil, Bill and Morris Wolfe. Signing On: The Birth of Radio in Canada. (Toronto: Doubleday Canada Limited, 1982) 58-60.
} 
Montreal Gazette, there was no need to outline the subject of the talk, because its content remained predictable within a certain range of topics like health, cooking and beauty.

Canadian Women's Hour, Women's Radio Review, and Homemakers constituted the regular daily women's programs aired by CFCF, Montreal's local English-language station, throughout the 1930s. The genre grew from nothing to its high point for the decade in 1931, reaching an average of 4 hours and 50 minutes a week. This great surge in women's programming occurred because CFCF supplemented its own programs Radio Homemakers' Institute, and Original Betty of the Air with the American network program, Edna Wallace Hopper. Although Hopper's program content was typical, offering beauty tips, it was unusual as one of the few American women's programs that appeared in the sample of Montreal stations for the decade. ${ }^{31}$ These women's programs were habitually daytime inclusions in the schedule, serving what was presumed to be the daytime audience. The daily inclusion of these programs made them an integral part of the schedule due to the consistent time block they filled.

Women's programming was one of the most common resources used by local independent radio stations to diversify and satisfy the needs of their daytime audiences. Neither Canadian nor American networks exhibited much interest in the early production of women's programming throughout the decade; it remained almost exclusively the preserve of local stations. Women's programming had an early start on CHNS as a regular morning feature in 1930. In that year the Women's Radio Institute constituted the majority, if not all, of the morning programming of the station at an average of 4 hours and 40 minutes weekly. The program began CHNS's broadcast day at 10:30 a.m. or 11:00 a.m. and remained fixed in the schedule until Mrs. Dexter's Women's Radio Hour replaced it in 1935. By the end of the decade, the contribution of women's programming to the weekly schedule increased to an average 7 hours and 5 minutes, but constituted a declining proportion of the total schedule. By then the women's programming included Good Morning Neighbor, available across the country, and Halifax's own Mrs. Dexter, a regular feature on CHNS from 1935 to 1939. The weekday morning position guaranteed women's programming a secure place in the schedule, unthreatened by network programming or competition from other types of programs. As a standardized feature of local programming, women's programming was marked by its regularity, frequency and overwhelmingly local nature.

The Depression became a time for family to huddle around the radio and find its entertainment increasingly at home. The programming void of the daytime hours was marked by the changes during the 1930s to accommodate the daily routines of women in the household. American serial dramas, traditionally a part of the evening schedule, shifted to the daytime schedule becoming associated with the female listener. Cooking and household programming as well as serial dramas found places in the late morning and afternoon, predating the transition of serial drama to the daytime schedule. Children's programming was clustered around suppertime and bedtime. Women found radio and radio found its daytime audience. Programming for women and children also differed from many genres since substantial quantities were local, not simply network broadcasts. Acceptance of women as listeners was also dependent on an acceptance of the possibility of passive listening in the background as they went about their

\footnotetext{
${ }^{31}$ Dunning, 314. Other less regular American inclusions were NBC Radio Kitchen in 1934 and Women in America in 1939.
} 
work, rather than the active family listening upon which the evening program schedule was based.

\section{Works Cited}

Bennett, Elizabeth Smith, personal interview, 15 July 1999.

Burke, Jean, personal interview, 18 February 2005.

Richard Butsch, The Making of American Audiences: From Stage to Television, 1750-1990.

Cambridge: Cambridge University Press, 2000.

Canada. Dominion Bureau of Statistics. General Statistics Branch, The Canada Year Book 1925.

Ottawa: King's Printer, 1925.

Canada. Dominion Bureau of Statistics. Department of Trade and Commerce, Canada, The

Canada Year Book 1940. Ottawa: King’s Printer, 1940.

Canadian Broadcasting Corporation, Canadian Broadcasting: An Account of Stewardship, excerpted from Canada. Parliament. House of Commons.

Special Committee on Radio Broadcasting. Minutes of Proceedings and Evidence, Nos. 2 and 3. Ottawa: King's Printer, 1939.

Cohen, Lizabeth. Encountering Mass Culture at the Grassroots: The Experience of Chicago

Workers in the 1920s, in Lawrence B. Glickman ed. Consumer Society in American History: A

Reader. Ithaca: Cornell University Press, 1999, 147-169.

Connor, Madeline, personal interview, 22 March 2005.

Doctor, Jennifer. The BBC and Ultra-Modern Music, 1922-1936: Shaping a Nation's Tastes.

Cambridge: Cambridge University Press, 1999.

Susan J. Douglas. Listening In: Radio and the American Imagination. Minnesota: University of

Minnesota Press, 1999.

Dunning, John. On the Air: The Encyclopedia of Old-Time Radio. New York: Oxford University Press, 1998.

Fraticelli, Hazel, personal interview, 18 February 2005.

Frith, Simon. "The Pleasures of the Hearth.” in Tony Bennett and Victor Burgin eds. Formations of Pleasure. London: Routledge \& Kegan Paul, 1983.

Gorman, Lyn, and David McLean. Media and Society in the Twentieth Century. Malden:

Blackwell Publishing, 2003.

Hayes, Norma, personal interview, 15 July 1999.

Hilmes, Michele. Radio Voices: American Broadcasting, 1922-1952. Minneapolis: University of Minnesota Press, 1997.

Johnson, Lesley."Radio and everyday life: The early years of broadcasting in Australia, 19221945." Media, Culture \& Society 3 (1981): 167-178.

Leacy, F.H., ed. Historical Statistics of Canada. “A.1 Estimated population of Canada. 18671977.” “A248-253 Number of households and average number of persons per household, Canada 1881-1976.” http://www.statcan.ca/english/freepub/11-516-XIE/sectiona/A1.csv, http://www.statcan.ca/english/freepub/11-516-XIE/sectiona/A248_253.csv accessed May 15, 2005.

MacLennan, Katherine, personal interview, 1 August 1999.

McChesney, Robert W. Telecommunications, Mass Media, and Democracy: The Battle for the Control of U.S. Broadcasting, 1928-1935. New York: Oxford University Press, 1993.

McNeil, Bill, and Morris Wolfe. Signing On: The Birth of Radio in Canada. Toronto: Doubleday Canada Limited, 1982. 
Morrison, Marian, personal interview, 31 August 1999.

Rosella, Louie. “Miriam Ross, 78, radio actress.” The Toronto Star 5 October 2000: B5. Scannell, Paddy, and David Cardiff. A Social History of British Broadcasting: Volume One 1922-1939 Serving the Nation. Oxford: Basil Blackwell, 1991.

Smulyan, Susan. "Radio Advertising to American Women in the 1920s: A Latchkey to Every Home.” Historical Journal of Film, Radio and Television 13 (1993): 299-314.

Smulyan, Susan. Selling Radio: The Commercialization of American Broadcasting 1920-1934. Washington: Smithsonian Institute Press, 1994.

Sterling, Christopher H., and John M. Kittross. Stay Tuned: A Concise History of American Broadcasting. 2nd ed. Belmont, California. Wadsworth Publishing Company, 1990.

Swartz, Jon, and Robert C. Reinehr. Handbook of Old-Time Radio: A Comprehensive Guide to Golden Age Radio and Listening and Collecting. Metuchen, New Jersey: The Scarecrow Press, Inc., 1993.

Vipond, Mary. Listening In: The First Decade of Canadian Broadcasting 1922-1932. Montreal \& Kingston: McGill-Queen’s University Press, 1992. 